\title{
Atendimento a queixa escolar nos serviços públicos de saúde mental da Bahia
}

\author{
Lygia de Sousa Viégas' ${ }^{1}$, https://orcid.org/0000-0002-2353-0384 \\ Klessyo do Espírito Santo Freire¹, https://orcid.org/0000-0001-5189-1278
}

Flávia Brandão Bomfim², https://orcid.org/0000-0001-7914-7790

\begin{abstract}
Resumo
O presente artigo analisa a atuação de psicólogos nos serviços públicos de saúde mental frente à demanda escolar na Bahia. Para tanto, os psicólogos que atuam nos Centros de Atenção Psicossocial (CAPS) responderam um questionário com perguntas sobre seu perfil profissional, o perfil das demandas escolares e as práticas e concepções adotadas no atendimento a tais demandas. A análise apontou, com relação ao perfil profissional, a presença de psicólogas mulheres, jovens, recém-formadas em instituições privadas de ensino. Quanto ao perfil do encaminhamento, destaca a presença de alunos pobres e negros, entre 6 e 12 anos, estudantes do ensino fundamental público, encaminhados por problemas de aprendizagem e comportamento. No atendimento, predomina uma visão individualizante da queixa escolar, embora haja profissionais que incorporaram elementos críticos. Espera-se, com a pesquisa, contribuir com os avanços no atendimento às demandas escolares, presentes em publicações no campo da psicologia escolar e educacional em uma perspectiva crítica.
\end{abstract}

Palavras-chave: Fracasso escolar ; saúde mental; aconselhamento psicológico.

\section{Attendance to the school complaint in the public services of Bahia's mental health services}

\begin{abstract}
This article analyzes the performance of psychologists in public mental health services in response to school demand in Bahia. To that end, the psychologists who work in the Psychosocial Care Centers (CAPS) answered a questionnaire with questions about their professional profile, the profile of the school demands and the practices and conceptions adopted in meeting these demands. The analysis pointed out, in relation to the professional profile, the presence of female psychologists, young, recently graduated in private educational institutions. Regarding the referral profile, the presence of poor and black students aged 6 to 12 years old, students of public primary education, referred by learning and behavior problems, stands out. In the care, an individualized view of the school complaint prevails, although there are professionals who incorporate critical elements. It expects, with the research, to contribute to the advances in the attendance to the school demands, present in publications in the field of the school and educational psychology in a critical perspective.
\end{abstract}

Keywords: Academic failure; mental health; psychotherapeutic counseling.

\section{Atención a la queja escolar en los servicios públicos de salud mental de Bahia}

\section{Resumen}

En el presente artículo se analiza la actuación de psicólogos en los servicios públicos de salud mental frente a la demanda escolar en Bahía. Para tanto, los psicólogos que actúan en los Centros de Atención Psicosocial (CAPS) respondieron a un cuestionario con preguntas sobre su perfil profesional, el perfil de las demandas escolares y las prácticas y concepciones adoptadas en la atención a tales demandas. El análisis apuntó, con relación al perfil profesional, la presencia de psicólogas mujeres, jóvenes, recién-diplomadas en instituciones privadas de enseñanza. Cuanto al perfil del encaminamiento, destaca la presencia de alumnos pobres y negros, entre 6 y 12 años, estudiantes de la enseñanza básica pública, encaminados por problemas de aprendizaje y comportamiento. Y la atención, predomina una visión individualizada de la queja escolar, aunque haya profesionales que incorporaron elementos críticos. Se espera, con la investigación, contribuir con los avances en la atención a las demandas escolares, presentes en publicaciones en el campo de la psicología escolar y educacional en una perspectiva crítica.

Palabras clave: Fracaso escolar; salud mental; orientación psicoterapéutica.

1 Universidade Federal da Bahia, Faculdade de Educação - Salvador, BA, Brasil.

2 Faculdade São Bento da Bahia - Salvador, BA, Brasil. 


\section{Introdução}

O presente artigo apresenta parte dos resultados de uma ampla pesquisa realizada no Estado da Bahia com o objetivo de analisar concepções e práticas de psicólogos que atuam nos serviços públicos de Assistência Social e Saúde atendendo demandas das escolas. Aqui, será contemplada parte dos resultados da pesquisa no campo da saúde mental.

Tal pesquisa toma como ponto de partida o estudo realizado por Viégas (2014a), no qual foram coletados dados relativos às concepções e práticas de psicólogos que atuam nos serviços públicos de educação na $\mathrm{Bahia}^{3}$, revelando que apenas 32 municípios possuíam psicólogos nas Secretarias de Educação (Viégas, 2016). A ausência desse profissional, no entanto, não significa que não há necessidade do trabalho de psicólogos educacionais ${ }^{4}$. Ao contrário, detectou-se que tais demandas são absorvidas em outros serviços públicos, com destaque para a Assistência Social e a Saúde Mental, para onde tem sido encaminhado número significativo de alunos com dificuldade de escolarização, apontando para a necessidade de compreender como tem se dado esse atendimento.

Tal relevância é reforçada quando se considera os últimos 30 anos de produção teórico-prática no campo da psicologia escolar e educacional brasileira. Como marco fundamental de tal produção, tem-se as pesquisas de Maria Helena Souza Patto $(1984,1990)$, importante psicóloga brasileira, que, à luz do materialismo-histórico-dialético, analisa as raízes históricas das concepções sobre o fracasso escolar. A autora aponta que a Psicologia, tradicionalmente, privilegiou aspectos intrapsíquicos dos alunos, com destaque para o desenvolvimento infantil, tanto do ponto de vista intelectual e motor como da personalidade, servindo para justificar cientificamente as desigualdades sociais, vistas como reflexo de (in)capacidades individuais.

Assim, Patto tece críticas impactantes não só ao cotidiano das escolas públicas brasileiras (Patto, 1990), mas também, se não essencialmente, à visão ideológica que domina a prática de psicólogos, por meio da qual as dificuldades de escolarização são traduzidas em temos psicologizantes, ignorando ou colocando em segundo plano a escola enquanto instituição inserida em uma sociedade dividida em classes, na qual prevalece o descaso e a precarização da educação brasileira, sobretudo a pública (Patto, 1984).

Trata-se de discussão consolidada na área de Psicologia Escolar e Educacional brasileira: diante do fracasso escolar, o psicólogo é chamado a contribuir, comumente por meio do encaminhamento de alunos por parte da escola para

3 Tal pesquisa é parte de estudo realizado em sete estados brasileiros (Santa Catarina, Paraná, São Paulo, Minas Gerais, Bahia, Rondônia e Acre), sob a coordenação da Profa. Dra. Marilene Proença Rebello de Souza, do Instituto de Psicologia da USP (Souza, Silva, \& Yamamoto, 2014).

4 Para análise do perfil dos psicólogos que atuam na rede pública de ensino da Bahia, bem como de suas concepções e práticas, ver Viégas (2014a; 2016). Publicações sobre a atuação de psicólogos no campo da assistência social também estão sendo produzidas. serviços de saúde. Ao receber tal demanda, mesmo diante de todas as críticas consolidadas na psicologia, o psicólogo, tradicionalmente, atua em um modelo clínico tradicional, realizando psicodiagnóstico e encaminhamento para terapia (Souza, 1996). Tal modelo possui viés individualizante e medicalizante, ao localizar no aluno ou em sua família as causas das dificuldades de escolarização. Essa maneira de atender e atender as demandas escolares é:

Reflexo de uma visão de mundo que explica a realidade a partir de estruturas psíquicas e nega as influências e/ ou determinações das relações sociais sobre o psiquismo, encobrindo arbitrariedades, os estereótipos e preconceitos de que as crianças de classes populares são vítimas no processo educacional e social. (Souza, 1997, p.35)

Tal análise converge com estudo de Cabral e Sawaia (2001), realizado em serviços de saúde no interior de São Paulo. Segundo a pesquisa, predomina entre psicólogos pesquisados a concepção de queixa escolar como resultante de problemas emocionais ou cognitivos dos alunos, de onde decorria uma atuação centrada na avaliação psicológica e no trabalho pedagógico, visando adaptar o aluno a um contexto escolar inquestionado.

De modo semelhante, Marçal e Silva (2006), em pesquisa com psicólogos que atuam em ambulatórios de saúde mental infanto-juvenis na região do Triângulo Mineiro, apontam que tais profissionais se sentiam mais seguros quando situavam problemas emocionais envolvidos na queixa escolar. $\mathrm{Na}$ inexistência de questões individuais, predomina o recurso ao encaminhamento para outros especialistas - neurologista, fonoaudiólogo, escolas especializadas ou reforço escolar.

Beltrame e Boarini (2013) desvelam que tal realidade se faz presente nos CAPSi do Paraná, denunciando que tal equipamento funcionava como ambulatório, em que o modelo clinico tradicional era privilegiado em detrimento da abordagem psicossocial. Para as autoras, esse fenômeno se relaciona com a ascensão da indústria farmacêutica e da psiquiatria biológica, que reforçam a ideia de saúde mental como objeto de consumo.

No caso do estado da Bahia, pesquisa de Freire (2017), realizada em um CAPSi de Salvador-BA, desvela que queixas escolares compareciam em $55 \%$ das crianças e adolescentes atendidas. A despeito dessa proporção, ainda predomina um viés individualizante e medicalizante no entendimento de tais queixas, que marca de maneira decisiva o atendimento oferecido, que desconsidera a complexidade da vida escolar.

Tal levantamento desvela que a visão medicalizante e individualizante das queixas escolares atravessa os serviços de saúde mental do país, já que o atendimento psicológico das queixas escolares tem priorizado o modelo clínico tradicional. Isso a despeito das diversas críticas fundamentadas na psicologia escolar e educacional, segundo as quais psicólogos ajudam a legitimar preconceitos, estigmas e a exclusão de alunos encaminhados por uma escola que historicamente têm produzido fracasso escolar. 
$\mathrm{Na}$ contramão dessa visão dominante, muitos estudos enfatizam que a análise dos problemas de escolarização deve considerar a complexidade do cotidiano escolar, atravessado que é por questões históricas, políticas, econômicas, sociais, institucionais, pedagógicas e relacionais. Segundo Tanamachi e Meira (2003), "em vez de nos dirigirmos a pessoas ou situações isoladas - o que tem efeito paralisador - buscamos as circunstâncias, porque estas podem ser transformadas" (p. 32). Dessa forma, o psicólogo pode "ajudar a escola a remover obstáculos que se interpõem entre os sujeitos e o conhecimento e a formar cidadãos por meio da construção de práticas educativas que favoreçam processos de humanização e reapropriação da capacidade de pensamento crítico" (p. 43).

Diante do debate efervescente na área, Souza coordenou a pesquisa realizada em sete estados brasileiros, a fim de conhecer as concepções e práticas de psicólogos no campo educacional público, verificando os impactos práticos da produção teórica avançada na área (Souza \& cols., 2014). Por meio de tal pesquisa, desvelou-se que na Bahia quase não havia psicólogos atuando na rede pública de ensino, indicando que as demandas escolares estavam sendo encaminhadas para os serviços de assistência social e saúde mental. A partir de tais dados, deu-se origem à pesquisa que agora se apresenta parcialmente, com a qual esperamos contribuir com a compreensão do atendimento à queixa escolar nos serviços públicos de saúde mental na Bahia, buscando consolidar uma atuação voltada à garantia da escolarização de qualidade para todos.

\section{Método}

A pesquisa objetivou identificar e analisar concepções e práticas desenvolvidas pelos psicólogos que atuam nos serviços públicos de Assistência Social e de Saúde na Bahia frente às queixas escolares. No presente artigo, focalizamos os seguintes objetivos específicos: traçar o perfil dos psicólogos que atendem demandas escolares nos CAPS do Estado da Bahia; traçar o perfil das demandas escolares para os CAPS; caracterizar as modalidades de atuação profissional dos psicólogos que atendem demandas escolares; e compreender as concepções que respaldam tais práticas.

A pesquisa inspirou-se no aparato teórico-metodológico da pesquisa anterior (Souza \& cols., 2014; Viégas, 2014a) ${ }^{5}$. Assim, o primeiro passo envolveu o contato (telefônico ou por correio eletrônico) com os CAPS do Estado da Bahia, a fim de identificar os psicólogos que atuam nesses serviços públicos atendendo demandas escolares, os quais foram convidados a participar da pesquisa6: na primeira etapa, os psicólogos responderam a um questionário padronizado; na segunda, seis profissionais selecionados a partir de análise do ques-

5 Vale ressaltar que a pesquisa foi aprovada pelo Comitê de Ética (Parecer 352.996).

6 A pesquisa foi realizada uma equipe de pesquisadores de quatro universidades baianas, as quais serão referenciadas oportunamente. Para sua realização, contamos com financiamento da FAPESB. tionário foram entrevistados; a terceira, por fim, envolveu a realização de entrevistas em grupo com cinco profissionais selecionados na segunda etapa.

O presente artigo focaliza os dados recolhidos na primeira etapa da pesquisa. Para tanto, o instrumento utilizado foi um questionário simples e de rápido preenchimento, constituído de perguntas (a maior parte de múltipla escolha, embora sempre com espaço para expressões pessoais) em torno dos seguintes aspectos: perfil do profissional; perfil do público alvo da atuação; modalidades de atuação; e filiação teórica.

Por meio da análise dos questionários, foi possível traçar o perfil tanto dos profissionais quanto das demandas escolares, além de possibilitar conhecer as práticas e concepções dos psicólogos das áreas de saúde mental no atendimento de tais demandas.

\section{Análise de dados}

Inicialmente, cumpre descrever, ainda que brevemente, o que é um CAPS infanto-juvenil. Segundo o Ministério da Saúde (Brasil, 2004, p. 23), trata-se de:

um serviço de atenção diária destinado ao atendimento de crianças e adolescentes gravemente comprometidos psiquicamente. Estão incluídos nessa categoria os portadores de autismo, psicoses, neuroses graves e todos aqueles que, por sua condição psíquica, estão impossibilitados de manter ou estabelecer laços sociais.

Ainda segundo o Ministério da Saúde (Brasil, 2004), cumpre a esses CAPS trabalharem em rede com outros aparelhos de saúde, além da educação e assistência social, visando o cuidado integral com a população infanto-juvenil. O Ministério da Saúde também explicita a preocupação em não medicalizar e patologizar a aprendizagem, revelada pelos índices de encaminhamentos escolares para esse equipamento (Brasil, 2014).

Atualmente, existem oito CAPSi na $\mathrm{Bahia}^{7}$, explicitando sua baixa cobertura e as dificuldades da rede de saúde mental infanto-juvenil no estado. Participaram da pesquisa 15psicólogas ${ }^{8}$ que atuam nos CAPSi da Bahia, sendo quatro da capital e 11 do interior.

\section{Perfil das profissionais}

Das 15 psicólogas participantes da pesquisa, 12 eram do sexo feminino e três do sexo masculino, com idades

7 Cf. http://sage.saude.gov.br/paineis/planoCrack/lista_caps.php?o utput=html\&ufs=29\&ibges $=\& \mathrm{cg}=\& \mathrm{tc}=\& \mathrm{re}$ giao $=\& \mathrm{rm}=\& \mathrm{qs}=\&$ ufcidad $\mathrm{e}=$ Bahia\&qt $=417 \% 20$ munic $\%$ C3\%ADpios $\&$ pop $=15203934 \&$ cor $=00$ 5984\&nonono=html\&title $=\&$ codPainel $=27$

8 Fizemos a opção de nos referirmos às profissionais no feminino considerando sua predominância de gênero na profissão, escolha feita também nas publicações do Sistema Conselhos de Psicologia. 
variando entre 26 anos e 60 anos, sendo a média de idade de 32,9 anos. Quanto à cor/raça, 10 declararam-se pardas e cinco se declararam brancas; nenhuma se declarou negra.

No que se refere à formação, treze psicólogas informaram que concluíram a graduação nos anos 2000, e apenas uma formou-se na década de 1980.Nove formaram-se em instituições privadas, e seis em instituições públicas. Todas realizaram pelo menos um curso após a graduação, sendo a maioria de especialização, tanto presencial como à distância, em diversas áreas, em especial no campo da saúde (coletiva, mental, hospitalar), psicopedagogia, clínica, neuropsicologia, psicodiagnóstico e políticas públicas.

Quanto ao início da trajetória profissional, chama a atenção que metade das participantes ingressou no mercado de trabalho como psicólogas no mesmo ano de ingresso na secretaria de saúde, o que sugere que o primeiro emprego foi em um serviço público. Cumpre ressaltar, nesse aspecto, que apenas nove declararam ser concursadas; outras quatro trabalham por meio de contrato, e duas não responderam à pergunta.

O cargo ocupado por todas as participantes era de psicóloga. Quanto à função, três especificaram outras funções: psicóloga clínica, técnico de referência e coordenadora.

A análise acima converge com estudo da profissão no Brasil (Bastos \& Gondim, 2010), que aponta a predominância de um perfil feminino, adulto-jovem, recém-formado em instituições privadas, com alguma pós-graduação, e que encontra no setor público oportunidade de primeiro emprego. Tal perfil também converge com a pesquisa sobre a atuação do psicólogo na rede pública de ensino da Bahia (Viégas, 2016), indicando, ainda, que o vínculo nos serviços públicos é precário, sem concurso.

\section{Perfil da demanda}

A quase totalidade das participantes da pesquisa afirmou receber, no CAPS em que atua, demandas escolares (apenas duas negaram ter essa demanda). Assim, a análise que se segue pautou-se nos questionários de 13 participantes.

No que se refere ao tipo de estabelecimento escolar que realiza encaminhamentos para os CAPS, a rede municipal comparece em todos os questionários, e apenas dois incluíram também a rede estadual. As demandas partem sobretudo do ensino fundamental I (12 questionários), do ensino fundamental II (10 questionários), do ensino médio (sete questionários) e da educação infantil (seis questionários). Foram referidas ainda demandas da educação especial/ inclusiva (quatro questionários), da creche (dois questionários) e da Educação de Jovens e Adultos (um questionário).

Tais demandas envolvem, essencialmente, o encaminhamento de alunos (referido pela totalidade das psicólogas), sendo indicados os seguintes motivos: problemas de comportamento (13 questionários); dificuldades de aprendizagem (12 questionários); problemas familiares (oito questionários); situação de violência na escola (oito questionários); necessidades educacionais especiais (oito questio- nários); problemas com drogas lícitas (cinco questionários) ou ilícitas (quatro questionários) e discriminação na escola (três questionários). O encaminhamento de professores ou outros funcionários da escola apareceu em três questionários, seja por motivo de violência ou discriminação na escola (um questionário), por sofrimento advindo do exercício profissional (dois questionários) ou por problemas com drogas lícitas ou ilícitas (um questionário).

A idade dos alunos encaminhados está assim distribuída: 6 a 9 anos (nove questionários); de 10 a 12 anos (nove questionários); de 13 a 15 anos (sete questionários); de 16 e 18 anos (três questionários); de 3 a 5 anos (dois questionários). Dez psicólogas dizem que há mais meninos encaminhados do que meninas. A despeito dessa prevalência, seis profissionais não notam diferenças de gênero nas demandas, ao passo que três afirmam que meninos possuem mais queixas de comportamento, tais como agitação e "hiperatividade". Quanto às meninas, uma psicóloga afirma que "há comportamentos que são mais tolerados em meninos, por isso quando se manifestam em meninas são alvo de preocupação"; duas psicólogas dizem que "as mulheres sofrem mais preconceito" e que "as meninas estão consumindo mais drogas lícitas e ilícitas, e estão agressivas".

No que diz respeito à etnia, nove psicólogas informaram o predomínio de pardos, oito psicólogas disseram que há mais negros, umacitou os brancos e uma, os indígenas. No entanto, a maioria afirma não haver diferença significativa em relação ao perfil étnico nas demandas (8 psicólogos, ou $69,2 \%$ ). Outras quatro psicólogas, ao contrário, destacam que tal diferença se expressa na maior presença de negros, pardos e indígenas.

Quanto ao nível socioeconômico, as psicólogas reconhecem a maior presença de alunos em condição de pobreza e extrema pobreza: oito assinalam um público que recebe entre meio e um salário mínimo; três se referem a um público que recebe menos de meio salário mínimo e três declararam que tal público recebe entre um e dois salários mínimos. Além disso, 12 psicólogas indicam que suas famílias recebem algum benefício do governo, com destaque para o Bolsa Família, presente na resposta de todas. O Benefício de Prestação Continuada (BPC) foi citado por oito psicólogas, havendo menção pontual ao Programa de Erradicação do Trabalho Infantil, Aposentadoria e Auxílio Reclusão.

Assim, em síntese, é possível afirmar que o CAPS tem recebido, de maneira significativa, demandas escolares. Tais demandas partem prioritariamente da rede pública de educação, com destaque para o ensino fundamental I e II, na forma de encaminhamento de alunos com idades entre 6 e 12 anos, sobretudo do sexo masculino. Dentre os motivos dos encaminhamentos, predominam os problemas de comportamento e de aprendizagem, embora também sejam significativas queixas de problemas familiares ou de violência escolar. Chama a atenção, ainda, a presença marcante de alunos negros e pardos, que vivem em condição de pobreza ou pobreza extrema. Tal perfil converge com diversas pesquisas na área, com destaque para Souza e Sobral (2007) e Encarnação Junior (2015). 
Com relação ao atendimento das demandas escolares, oito psicólogas afirmam que ele ocupa a menor parte do tempo de trabalho $(61,5 \%)$, enquanto que, para 5 psicólogas, essa é a maior ou metade da demanda atendida. Duas psicólogas, por fim, disseram não atender tais demandas, assim explicando essa decisão:

Faço escuta das demandas e oriento sobre as possibilidades de intervenção e encaminhamentos que podem ser adotados. (Participante 14)

Diversas demandas chegavam e chegam ao CAPSi, como por exemplo a criança que apresenta dificuldade de aprendizagem e na aprendizagem, porém o CAPSi não atende esta demanda, pois não se trata de transtornos mentais graves e severos. Faço encaminhamentos para psicopedagoga e psicóloga clínica. (Participante 15)

Embora não mais atendam tais demandas, essas psicólogas responderam à pesquisa à luz de experiências anteriores, de forma que elas foram incorporadas à análise.

\section{O atendimento das demandas escolares: práticas e concepções}

A análise dos questionários das 13 psicólogas que atendem demandas escolares nos CAPS desvela que a quase totalidade (11 psicólogas) indica os alunos como público-alvo da atuação, ora exclusivamente (cinco psicólogas), ora de maneira conjunta com a família (duas psicólogas), ora de maneira conjunta com a escola (uma psicóloga), ora articulando todos esses atores (três psicólogas).

Com relação à modalidade de atuação, a maior parte realiza avaliação psicológica (9 psicólogas), sendo que apenas duas utilizam testes. Os diagnósticos mais produzidos são: déficit cognitivo (oito questionários), problemas emocionais (oito questionários), desestruturação familiar (oito questionários), deficiência mental leve/moderada (seis questionários), transtorno de personalidade (cinco questionários), disfunção neurológica (três questionários) e TDAH (três questionários). Também houve menção à desnutrição, problemas psicomotores, prontidão/imaturidade e dislexia, em um questionário cada.

Além da avaliação psicológica, o atendimento clínico individual de alunos figura na maioria dos questionários (oito), ao lado do atendimento clínico familiar (cinco questionários). Quanto aos objetivos pretendidos, destaca-se a adaptação do aluno à escola e ao contexto social, bem como a correção de comportamentos e ensino de habilidades sociais e cognitivas, tal como se nota nas respostas abaixo:

Na compreensão dos problemas emocionais que atingem os alunos e suas famílias e a inter-relação destes com o contexto escolar. (Participante 2)

Melhorar o comportamento disfuncional, reforçar comportamentos, ensinar habilidades sociais e treino cognitivo (atenção, memória, linguagem e raciocínio). (Participante 7)

Adequação desses usuários na comunidade tanto escolar, quanto social, aprendizagem de conteúdos para alcançar objetivos de vida e formação. (participante 8)

Trabalhar o conflito atual e seus motivos. Trabalho com a abordagem psicoterapia breve. (Participante 12)

Dessa maneira, pode-se afirmar que o atendimento das demandas escolares nos CAPS tem priorizado o aluno (seja individualmente, seja com sua família), o qual tem sido submetido à avaliação psicológica e atendimento clínico individual com vistas ao ajustamento à escola. Trata-se de forma de atendimento das demandas escolares criticada à exaustão na área de psicologia escolar e educacional (Patto, 1984, 2009; Freller, 1997). Tais práticas desvelam o predomínio de uma visão individualizante da queixa escolar (Souza, 1997). De fato, à pergunta sobre o que entendem por queixa escolar, a maioria das psicólogas indica que a mesma decorre de fatores cognitivos, sociais, emocionais e familiares, ou seja, fatores externos à escola, como na resposta abaixo:

Entendo como sendo as dificuldades apresentadas pelos alunos principalmente quanto à aprendizagem escolar; mas também problemas apresentados em relação a comportamentos e condutas sociais observados no meio escolar que estão interferindo de forma negativa no seu aprendizado e no seu desenvolvimento social. As queixas surgem a partir das observações feitas pelos educadores (professores e outros profissionais da escola) e pela família. (Participante 10)

Deve-se destacar que também os professores ou outros funcionários da escola têm sido atendidos em modelo clínico individual (dois questionários), conforme relato abaixo:

Um caso, o problema foi desencadeado por estresse pós trauma. Teve duas situações envolvendo violência contra professores, que estão afastados das salas de aula. No caso mais recente, a pessoa não tem condições psicológicas para voltar a lecionar, mesmo desejando muito. É um caso de depressão. Já tentou e não conseguiu, hoje tenta mais um afastamento, e depois, quem sabe, conseguir exercer alguma outra atividade escolar fora da sala de aula. (Participante 10)

Para além das estratégias individuais de atendimento às demandas escolares, foram encontradas respostas que apontam para práticas de caráter grupal. São psicólogas que realizam grupos com famílias (cinco questionários), com crianças (quatro questionários) e com professores (quatro questionários), havendo, ainda, três questionários que afirmam a prática de assessoria às escolas. 
Dentre as psicólogas que adotam estratégias grupais de atendimento, destaca-se o objetivo baseado na política de saúde mental infanto-juvenil de dar suporte à escola, vista como espaço de reinserção e reabilitação social: "O papel do CAPS é promover e cuidar da saúde mental e no contexto escolar tal objetivo se debruça sobre a reinserção social" (PS5). Houve, também, a presença de psicólogas que propõem uma atuação mais crítica em relação às demandas escolares, de forma a problematizar essas queixas:

Tirar a criança do centro da queixa. Desmistificar a questão dos transtornos, compartilhando saberes da saúde mental. Orientar sobre os processos da infância "normal". Debater sobre o lugar ocupado pela criança e seu bem-estar no mundo, na família e na escola. Empoderar pais e educadores para terem autonomia de atuação com as crianças uma vez que o saber médico ocupa um lugar primordial para essas pessoas, o "sujeito suposto saber". (Participante 1)

O psicólogo pode contribuir na compreensão da escola como contexto de desenvolvimento, auxiliando na compreensão da relação professor-aluno e do contexto escolar como um todo com o aluno. (Participante 3 )

Através da escuta apurada, imparcial e especializada, compreender a demanda na sua complexidade em uma perspectiva sistêmica, dando o suporte necessário e dentro das reais necessidades do sujeito. (Participante 15)

Assim, foi possível detectar a presença de uma compreensão crítica da queixa escolar (Souza, 2007), implicando em um atendimento que visa a desmistificar e/ou problematizar o diagnóstico, fundamentalmente em parceria com a escola:

Assim que a demanda foi recebida nos dirigimos à escola para conversar sobre o caso encaminhado que se tratava de uma criança supostamente hiperativa que estava abalando a estrutura de todos, professores e crianças. Conversamos com a professora e a diretora e levantamos questões sobre o TDAH e o comportamento esperado das crianças da atualidade. Desmistificamos o diagnóstico e a necessidade da medicalização, o que gerou empoderamento da equipe para lidar com o caso de forma mais tranquila. (participante 1)

A partir de uma compreensão biopsicossocial do ser humano, o psicólogo pode contribuir no sentido de explorar a dimensão psicossocial que está contida a instituição escolar, buscando a reflexão e desconstrução de sistemas tradicionais que focam apenas em problemas de aprendizagem e se esquecem da complexidade humana. (participante 15)

A compreensão crítica das demandas escolares, no entanto, aparece misturada com uma visão reprodutivista de escola (Patto, 1990):

Parte do atual sistema de educação parece excluir, afastar as crianças. Trata-se de uma escola que precisa de ajuda em todos os sentidos, que se perde em seus objetivos rasos e em seu fazer maçante que não atrai, mas repele, que não estimula, mas entedia e reprime. Uma escola com potencial adoecedor principalmente para os professores.(Participante 1)

A escola, por ser um aparelho ideológico do Estado, segundo Althusser, acaba por desempenhar uma função de controle e adequação dos indivíduos para o convívio social e profissional segundo uma lógica do sujeito produtivo, e por meio das discussões e disciplinas essa lógica é reafirmada. Deste modo, vejo que a queixa escolar tem relação com o que, pela avaliação dos profissionais da instituição educacional, não se enquadra com o que é esperado enquanto prática/postura do aluno e, portanto, deve ser questionada e erradicada a fim de que essa adequação do sujeito produtivo possa ser efetiva. (Participante 13)

Cumpre ressaltar que, independentemente de uma modalidade de atuação individual ou coletiva,à exceção de duas psicólogas, todas as participantes mencionaram fazer contato com as escolas, seja por meio de reuniões (seis psicólogas), visitas (cinco psicólogas), comunicação por meio de documentos (seis psicólogas) ou conversa telefônica (uma psicóloga).

A maioria das psicólogas afirma que os objetivos de sua proposta de atuação são parcialmente atingidos, apontando como desafios questões estruturais do CAPS ou a falta de apoio familiar e escolar. No que se refere às questões estruturais, destacam o excesso de demandas e a falta de transporte para visita às escolas. Uma psicóloga descreve a sensação de "apagar incêndio com um dedal" (Participante 1). Quanto à falta de apoio das escolas, ressalta-se a resposta de uma psicóloga:

As escolas apresentam dificuldade tanto na manutenção de alunos com expressão de agressividade quanto com necessidades especiais de aprendizado. Alguns casos avançam quando acionadas as Secretarias de Educação e Ministério Público. (participante 4)

Por fim, sete psicólogas afirmaram encaminhar a demanda, sobretudo para neurologista, psiquiatra e psicopedagogo, embora haja menção pontual à educação especial, CRAS, fonoaudiólogo, oftalmologista ou ambulatório. No que diz respeito aos encaminhamentos, uma psicóloga afirma não atingir o objetivo pretendido:

Como preciso encaminhar para um serviço mais especializado, geralmente as ações realizadas nos atendimentos posteriores (ambulatório de psicologia) não contemplam de forma satisfatória. Muitas vezes, limitase a uma intervenção fragmentada e tendenciosa que se restringe as informações levadas pelos responsáveis, sem uma investigação adequada do fenômeno. Percebo muitas vezes formação insuficiente e práticas profissionais antiéticas, além de um foco em especialidades médicas na busca de possíveis diagnósticos. (Participante 15) 
Ainda no que tange à atuação profissional, a significativa maioria afirmou ter autonomia (nove psicólogas), às quais se somam outras três psicólogas que afirmaram ter autonomia parcial. Apenas uma psicóloga disse não ter autonomia no trabalho.

Dentre as teorias mais citadas pelas psicólogas, destacam-se a comportamental, cognitivista, neurociências, psicanálise, teoria sistêmica e Gestalt. Já os autores mais citados foram Vigotski, Piaget, Paulo Freire, Pichon Riviére, Foucault, Deleuze, Guatarri e Bourdieu. Destaca-se que foi comum a referência de autores e teorias de diferentes matrizes epistemológicas por parte de uma mesma profissional. Apenas uma psicóloga fez referência a autores da psicologia escolar e educacional em uma perspectiva crítica, destacando as contribuições de Patto para o entendimento de demandas escolares.

Algumas psicólogas disseram apoiar o trabalho em documentos de referência no campo da saúde mental, com destaque para os conceitos de clínica ampliada, humanização, integralidade, equidade.

No que diz respeito ao impacto da formação básica em psicologia no atendimento das demandas escolares, as psicólogas citaram disciplinas essenciais, com destaque para Psicologia Escolar/Educacional/da Educação, Psicologia do Desenvolvimento, Processos e Problemas de Ensino e Aprendizagem, Psicologia Social e Psicopatologia. Houve menção, ainda, às disciplinas de técnicas de exame e avaliação psicológica. Também foi enfatizada a importância do estágio supervisionado na área, por possibilitar observar o contexto escolar e dialogar com professores e alunos, criando a oportunidade de vivenciar a prática. A experiência de estágio na clínica infantil também foi citada.

\section{Considerações finais}

A partir da análise dos questionários, é possível afirmar que as psicólogas participantes da pesquisa que atendem demandas escolares nos CAPS da Bahia, em sua maioria, compreendem a queixa escolar através de um modelo clínico tradicional. Nesse sentido, ainda é dominante uma visão medicalizante do fracasso escolar (Viégas, 2014b), presente tanto nas práticas quanto nas concepções que Ihes dão sustentação ${ }^{9}$.

No entanto, também se nota que algumas profissionais incorporam importantes elementos da psicologia escolar e educacional em uma perspectiva crítica, trabalhando no sentido de desconstruir estigmas e preconceitos em relação aos alunos encaminhados.

Nesse sentido, apesar dessa presença ser modesta e circunscrita, entendemos que ela tem uma potencialidade de afetar a atuação de psicólogas que atendem demandas escolares nos CAPS baianos.Além disso, destacamos a potencialidade do documento "Recomendações de práticas

9 Vale ressaltar que, apoiados em Angelucci (2007), não entendemos que o atendimento clínico seja sinônimo de perspectiva individualizante ou medicalizante. não medicalizantes para profissionais e serviços de educação e saúde", do Fórum sobre Medicalização da Educação e da Sociedade (2012), considerando que o mesmo apresenta uma série de elementos que podem vir no sentido de incrementar a prática de psicólogos. É no intercâmbio de ideias e na formação para uma atuação crítica que será possível construir práticas de atendimento às demandas escolares que efetivamente contribuam com a construção de uma escola que acolha as diferenças de forma bem-sucedida.

\section{Referências}

Angelucci, C.B. (2007). Por uma clínica da queixa escolar que não reproduza a lógica patologizante. In: Souza, B.P. (Org.), Orientação à Queixa Escolar (pp. 353-378).São Paulo: Casa do Psicólogo.

Bastos, A.V.B.; Gondim, S.M.G. (2010). O trabalho do psicólogo no Brasil. Porto Alegre: Artmed.

Beltrame, M.M.; Boarini, M.L. (2013). Saúde mental e infância: reflexões sobre a demanda escolar de um CAPSi. Psicologia: ciência e profissão, 33(2). Recuperado: 30 mar. 2017. Disponível:http://www.scielo.br/scielo.php?script=sci_arttext\&pid= S141498932013000200007\&lng=en\&nrm=iso.

Brasil. Ministério da Saúde. Secretaria de Atenção à Saúde. Departamento de Ações Programáticas Estratégicas (2004). Saúde mental no SUS: os centros de atenção psicossocial. Brasília: Ministério da Saúde.

Brasil. Ministério da Saúde. Secretaria de Atenção à Saúde. Departamento de Atenção Especializada e Temática (2014). Fórum Nacional de Saúde Mental Infanto-juvenil: Recomendações: de 2005 a 2012. Ministério da Saúde, Secretaria de Atenção à Saúde, Departamento de Atenção Especializada e Temática. Brasília, DF: Ministério da Saúde.

Encarnação Junior, A.C.D. (2015). Entre crianças, queixas escolares e atendimento psicológico: um estudo sobre o serviço de psicologia de uma universidade pública baiana. (Dissertação de Mestrado). Faculdade de Educação, Universidade Federal da Bahia, Salvador, BA.

Freire, K.E.S. (2017). Educação e Saúde Mental: Uma análise sobre queixas escolares em um CAPSi de Salvador- BA. 2017. (Dissertação de Mestrado). Faculdade de Educação, Universidade Federal da Bahia. Salvador, BA.

Cabral, E.; Sawaya, S. M. (2001). Concepções e atuação profissional diante das Queixas escolares: os psicólogos nos serviços públicos de saúde. Estudos Psicologia, Natal, 6( 2), 143-155.

Freller, C.C. (1997). Crianças portadoras de queixa escolar. In: Machado, A.M.; Souza, M.P.R. (Orgs.), Psicologia escolar: em busca de novos rumos (pp. 63-78). São Paulo: Casa do Psicólogo. 
Fórum sobre Medicalização da Educação e da Sociedade. Grupo de Trabalho Educação \& Saúde (2012). Recomendações de práticas não medicalizantes para profissionais e serviços de saúde e educação. São Paulo. Recuperado: 03 nov. 2016. Disponível: http://medicalizacao.com.br/wp-content/uploads/2012/11/ RECOMENDACOES.pdf.

Marçal, V.P.; Silva, S.M.C. (2006). A queixa escolar nos ambulatórios públicos de saúde mental: práticas e concepções. Psicologia Escolar e Educacional, 10, 121-131.

Patto, M.H.S. (1984). Psicologia e Ideologia: Uma introdução crítica à Psicologia Escolar. São Paulo: T.A. Queiroz.

Patto, M.H.S. (1990). A produção do fracasso escolar: Histórias de submissão e rebeldia. São Paulo: T.A. Queiroz.

Patto, M.H.S. (2009). De gestores e cães de guarda: sobre psicologia e violência. Temas em psicologia, 17(2), 405-415.

Sala de Apoio à Gestão Estratégica Ministério da saúde. Recuperado: 01 nov 2016. Recuperado: 20 nov. 2016. Disponível em: http:// sage.saude.gov.br/paineis/planoCrack/lista_caps.php?output=ht ml\&ufs $=29 \&$ ibges $=\& \mathrm{cg}=\& \mathrm{tc}=\& \mathrm{re} \_$giao $=\& \mathrm{rm}=\& \mathrm{qs}=$ \&ufcidade $=$ Bah ia\&qt=417\%20munic\%C3\%ADpios \&pop=15203934\&cor $=005984$ \&nonono=html\&title $=\&$ codPainel $=27$

Souza, B.P. (2007). Orientação à Queixa Escolar. São Paulo: Casa do Psicólogo.

Souza, B.P.; Sobral, K.R. (2007). Características da clientela da Orientação à Queixa Escolar: revelações, indicações e perguntas. In: Souza, B.P. (Org.), Orientação à Queixa Escolar (pp. 119-134). São Paulo: Casa do Psicólogo.
Souza, M.P.R. (1996). A queixa escolar e a formação do psicólogo. (Tese de Doutorado). Instituto de Psicologia da Universidade de São Paulo, São Paulo, SP.

Souza, M.P.R. (1997) A queixa escolar e o predomínio de uma visão de mundo. In: Machado, A.M.; Souza, M.P.R. (Orgs.), Psicologia escolar: em busca de novos rumos (pp. 17-33). São Paulo: Casa do Psicólogo.

Souza, M.P.R.; Silva, S.M.C.; Yamamoto, K. (2014). Atuação do psicólogo na educação básica: concepções, práticas e desafios. Uberlândia: EDUFU.

Tanamachi, E.; Meira, M.E.M. (2003) A atuação do psicólogo como expressão do pensamento crítico em psicologia e educação. In: Meira, M.E.M.; Antunes, M.A.M. (Orgs.), Psicologia escolar: práticas críticas (pp. 11-62). São Paulo: Casa do Psicólogo.

Viégas, L.S. (2014a) Atuação do psicólogo na rede pública de educação da Bahia. In: Souza, M.P.R; Silva, S.M.C.; Yamamoto, K. (Orgs.), Atuação do psicólogo na educação básica: concepções, práticas e desafios (pp. 99-112). Uberlândia: EDUFU.

Viégas, L.S. (2014b) Direitos humanos e políticas públicas medicalizantes de educação e saúde: uma análise crítica a partir da psicologia escolar e educacional. In: Viégas, L.S.; Ribeiro, M.I.S.; Oliveira, E.C.; Teles, L.A.L. (Orgs), Medicalização da educação e da sociedade: Ciência ou mito? (pp. 121-140). Salvador: EDUFBA.

Viégas, L.S. (2016) O atendimento à queixa escolar na educação pública baiana. Revista Entreideias, 5(1), 57-72.

Recebido em: 12/12/2016 Aprovado em: 10/07/2017

\section{Sobre os autores}

Lygia de Sousa Viégas (lyosviegas@gmail.com)

Faculdade de Educação da Universidade Federal da Bahia. Doutora em Psicologia Escolar e do Desenvolvimento Humano pelo IP-USP. Salvador-BA. https://orcid.org/0000-0002-2353-0384

Klessyo do Espírito Santo Freire (klessyo@gmail.com)

Faculdade de Educação da Universidade Federal da Bahia. Mestre em Educação pela FACED-UFBA. Salvador-BA. https://orcid.org/0000-0001$5189-1278$

Flávia Brandão Bomfim (flaviabomfim_@hotmail.com)

Núcleo de Atendimento à Criança com Paralisia Cerebral (NACPC). Psicóloga pela Faculdade São Bento da Bahia. Salvador-BA. https://orcid. org/0000-0001-7914-7790 